Mónica Montaño Reyes

Marco Antonio Cortés Guardado*•

\title{
Perfil político de los diputados mexicanos federales del PAN y PRI de la LXI Legislatura: apuntes para un estudio cualitativo de los políticos
}

Introducción

En la actualidad, algunos de los discursos relacionados con el fracaso de la democracia se refieren constantemente al retroceso de las élites políticas en cuanto a la rendición de cuentas, a la habilidad en el diseño de las

El descontento ante la democracia ha provocado que el estudio del capital humano que dirige las instituciones representativas cobre relevancia. En este artículo se analiza el perfil político de 382 diputados federales del Partido Acción Nacional (PAN) y del Partido Revolucionario Institucional (PRI) de la LXI Legislatura. El análisis contempla sus competencias profesionales, su trayectoria y su experiencia política. Los resultados muestran datos relevantes sobre los personajes que ejercen los puestos de representación política en México; la revisión de sus competencias personales y de su trayectoria profesional lleva a concluir que la carrera política es un factor de gran importancia para el mejor funcionamiento de la democracia representativa.

Palabras clave: clase política, legisladores, carrera política, democracia representativa.

- Profesora de asignatura del Departamento de Estudios Políticos de la Universidad de Guadalajara y del Departamento de Estudios Políticos y Socio-jurídicos del Instituto Tecnológicos de Estudios Superiores de Occidente monicamontano@iteso.mx - Profesor-investigador titular C del Departamento de Arte, Educación y Humanidades del Centro Universitario de la Costa. Miembro del Sistema Nacional de Investigadores, nivel II marco.cortes@cuc.udg.mx políticas públicas y a la corrupción (Crouch, 2004; Pharr y Putnam, 2000; Pasquino, 1999). Por ello, es muy importante analizar la calidad de la clase política para determinar el beneficio o perjuicio que esta le trae a las democracias.

En el capítulo dedicado a las élites en Theory of democracy revisited, Sartori (1987) señala que "la verdad es que la democracia depende [...] de la calidad de sus líderes". La frase recuerda a Tucídides, quien hablaba del esplendor de Atenas atribuyéndolo a la posición de Pericles, a su habilidad e integridad para ejercitar un control independiente sobre la multitud. De acuerdo con Sartori, la democracia es terriblemente difícil, "[...] tan difícil que sólo las élites expertas y rendidoras de cuentas pueden salvarla de los excesos del perfeccionismo, de la demagogia y 
de la degeneración de los partidos políticos. Y es por eso que el liderazgo adecuado es vital a la democracia”. Por ello concluye que el mejor sistema electoral es aquel que otorga las herramientas para escoger los mejores liderazgos.

Juan Linz (1997), por su parte, también insistió en que la calidad de la clase política es fundamental para hacer funcionar la democracia. Agregó que la calidad de los políticos en cargos públicos no es tan importante como la clase política, definida como la gran mayoría que en gobierno y en oposición aspira a ganar votos. Linz enlistó algunos indicadores para la calidad de la clase política, los cuales tomaron en cuenta características deseables e indeseables de los políticos, e incluían: vocación política, compromisos con la colectividad, cantidad de corrupción, y contenido del discurso en el enfrentamiento electoral con el contrincante y con los votantes.

Cabe resaltar, con todo, que el concepto político de calidad sigue sin ser aceptado por la comunidad académica de manera consensuada; por lo que conviene presentar una discusión de este desde la perspectiva de distintos autores, según se hará a continuación.

\section{El político de calidad favorece la democracia}

Desde la perspectiva de la calidad democrática, un político de calidad sería aquel que favorece el desarrollo democrático de su país. ${ }^{1}$ Pero ¿de qué forma los políticos favorecen la democracia? Para autores como Weber (2001 [1919]), ${ }^{2}$ Sartori (1987), Linz (1997) y Przeworski (1999) ${ }^{3}$ un

I. Como ha sido mencionado por Morlino, en la definición de la calidad democrática, las instituciones y los mecanismos deben favorecer la democracia en su país para considerarse de calidad.

2. En El político y el científico Weber (200I [1919]) sostiene que un político debe responder a una causa y tener responsabilidad social en sus acciones.

3. Me refiero a su libro Democracy, Accountability and Representation (I999) donde señala la importancia de que los políticos tengan espíritu público para lograr la verdadera representatividad. 
Perfil político de los diputados mexicanos federales del PAN y PRI de la LXI Legislatura: apuntes para un estudio cualitativo de los políticos

político favorece la democracia si ha construido su carrera política a partir de motivaciones de interés público y de vocación política, y si cuenta con competencias profesionales que enriquezcan su desempeño en el cargo público. De manera que únicamente se ha hecho énfasis en evaluar la clase política en el plano potencial, o de calidad ex - ante, en el plano de los perfiles y trayectorias de sus integrantes, dejando así de lado su desempeño en el cargo público.

Dicha visión ha sido fortalecida desde otros campos de la literatura, los cuales se han ocupado de los actores políticos y de su relación con las instituciones democráticas. Así, por ejemplo, el concepto quality politician ha sido referido mayoritariamente en el campo de la economía política, donde se muestra al político de calidad como aquel que tiene el respaldo de una carrera política coincidente con los presupuestos normativos de la teoría democrática. ${ }^{4}$

Conviene precisar que el debate no radica en si son los actores quienes hacen las instituciones o si son las instituciones las que hacen a los actores, ya que ambos enfoques nos ayudan a explicar fenómenos diversos y están íntimamente relacionados, por lo que explicar una causalidad que emana de unos hacia otras es un debate que no se pretende desarrollar aquí. Aun así, los economistas políticos han insistido en que el político de calidad es el resultado inmediato del buen funcionamiento democrático, el cual favorece una buena carrera y trayectoria política. Entonces, la definición de político de calidad está íntimamente relacionada, por un lado, con el buen reclutamiento político que llevan a cabo los partidos y la clase política establecida (Casellia y Morelli, 2001), usando los controles existentes

4. La democracia, como régimen político, conlleva una serie de preceptos normativos y valores que son inherentes en la construcción de su teoría y filosofía. A pesar de que la ciencia política evite cualquier valor normativo en sus formulaciones, en este caso me refiero a los valores normativos inherentes a la democracia y que han guiado la investigación evaluativa de las instituciones dentro del marco de la calidad de la democracia. 
para ingresar en la política y el bajo nivel de oportunismo (Besley, Pande y Rao, 2005) y, por el otro, con la buena selección electoral de los ciudadanos por los candidatos (Poutvaara y Takalo, 2005).

Un político es de calidad si beneficia a la democracia. Y la beneficiará con la forma en que construye su carrera política. En la democracia, lo contrario de las carreras políticas son las prácticas tradicionalmente consideradas autoritarias, tales como el oportunismo y el compadrazgo decisivo en la designación de candidaturas o puestos políticos, y la presencia de familias gobernantes, las cuales están estrechamente vinculadas a las teorías de la renovación de las élites. ${ }^{5}$ En otras palabras, a la democracia le convienen las carreras políticas que estén abiertas al reclutamiento de los partidos políticos y estén motivadas por la vocación y la profesionalización política.

La trayectoria política presenta filtros de selección que han sido resaltados por algunos autores (Norris, 1997; Alcántara, 2008; Siavelis y Morgenstern, 2008; Rehfeld, 2010). En un modelo ideal, el primer filtro serían las instituciones políticas, las cuales, con sus requisitos legales, podrían seleccionar entre un universo de políticos a los más capacitados para convertirse en diputados o presidentes. El segundo filtro serían las élites políticas, conformadas por los mentores que eligen a sus sucesores o discípulos, cuya habilidad política sería puesta a prueba con voluntariados y otras actividades no pagadas. En un tercer momento, los ciudadanos serían los próximos en depurar el universo de candidatos al informarse sobre la calidad de ellos y elegir, en virtud de su habilidad y cultura política, al mejor (Przeworski, 1999).

Concentrándonos en el caso de México, se puede observar que el análisis se ha enfocado, sobre todo, en la élite 
Perfil político de los diputados mexicanos federales del PAN y PRI de la LXI Legislatura: apuntes para un estudio cualitativo de los políticos

del poder que prácticamente conformó el PRI, como partido hegemónico en la historia del país (Ai Camp, 2002). El PRI, luego del triunfo del PAN en el año 2000, trajo al escenario nuevas formas de reclutamiento político y pluralidad en la escena política. Es por lo anterior que la selección de casos de estudio es fundamental para seguir observando el comportamiento de los representantes de los partidos políticos de México.

\section{Casos de estudio}

La teoría económica propone analizar la calidad de los políticos. En consecuencia, en este estudio se procedió a analizar las biografías de los diputados federales de los 2 partidos políticos con más presencia en la LXI Legislatura en la Cámara de Diputados de México y que han ocupado la presidencia de la república. ${ }^{6}$ Los datos se obtuvieron del sitio oficial de Sistema de Información Legislativa de la Secretaría de Gobernación. ${ }^{7}$ En total se analizaron 382 biografías de diputados federales del PRI y del PAN. Las dimensiones consideradas fueron: competencias profesionales, reclutamiento político y experiencia política. Una vez hecho esto, los resultados se dividieron por partido político, tipo de elección y género.

\section{Las competencias profesionales de los diputados federales}

Los indicadores revisados para el análisis de las competencias profesionales fueron: a) nivel de educación y grado académico, b) profesión exitosa y c) competencia en la comisión legislativa.

6. Los datos son parte de una tesis doctoral donde se analizaron cuatro países: Italia, España, México y Argentina. Debido a la cantidad de parlamentarios en cada país se seleccionaron los dos partidos políticos con mayor presencia en cada uno de ellos. En el caso de México fueron PRI y PAN.

7. Durante el periodo que se realizó este estudio, el sitio web aparecía con la dirección www.sil.gob.mx. Ahora se puede consultar en www.sil.gobernacion.gob.mx 
a) Nivel de educación y grado académico

En promedio, el $65 \%$ de los diputados analizados tienen licenciatura y alrededor del $20 \%$ un posgrado. La educación técnica y básica cuenta con porcentajes bajos; cifras que denotan la existencia de una educación superior entre los diputados federales.

Gráfica 1. Nivel educativo en la LXI Legislatura

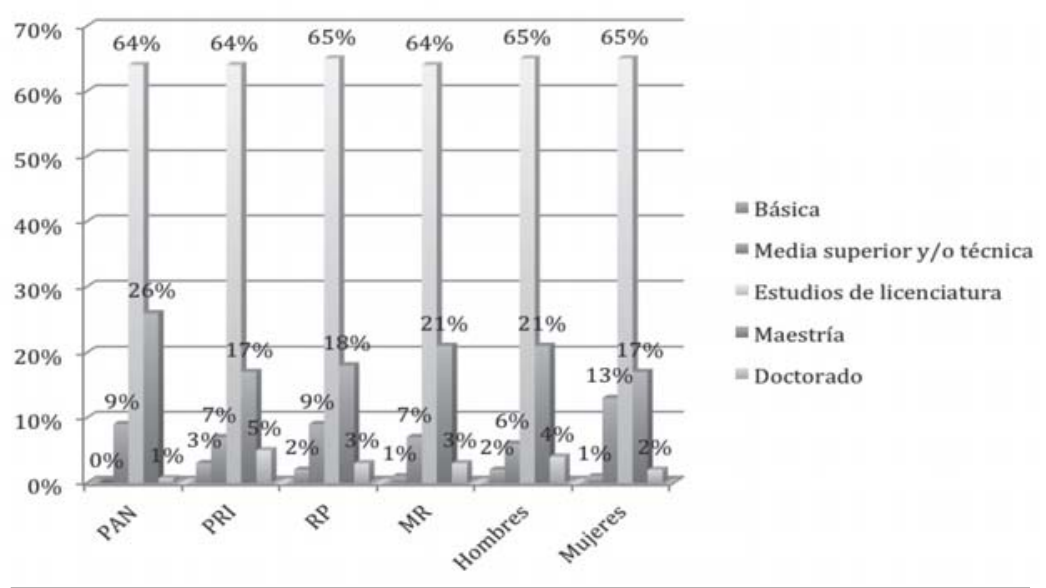

n=PAN (141), PRI (241), RP (126), MR (256), hombres (280), mujeres (102)

Pero además del grado académico, ¿qué especialidades están más representadas en el Congreso? En este aspecto las disciplinas más presentes en el Congreso (51\% de los diputados) están en las áreas de derecho, administración y economía, y notablemente menos en las ingenierías, ciencias sociales, educación y medicina.

\section{b) Profesión exitosa}

Además de la educación y el grado académico, autores como Galasso y Nachinni (2009) resaltan la importancia del éxito profesional alcanzado antes de entrar en los partidos. Esto aumenta el valor del político en el cargo público, 
Perfil político de los diputados mexicanos federales del PAN y PRI de la LXI Legislatura: apuntes para un estudio cualitativo de los políticos

Gráfica 2. Grados educativos más presentes en la LXI Legislatura

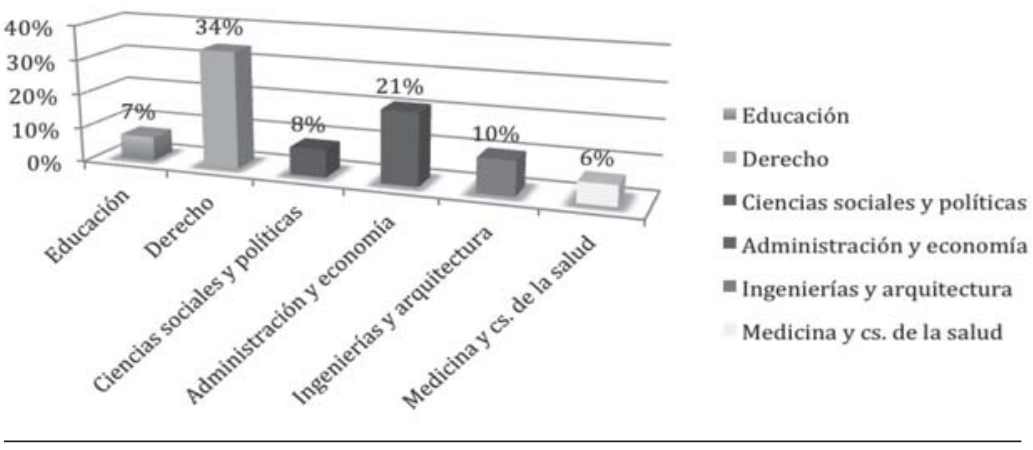

$\mathrm{n}=382$

puesto que indica que ha accedido al cargo luego de haber triunfado profesionalmente.

En la muestra analizada, se observó cuál era la profesión de los actuales diputados antes de la obtención su primer puesto. Después se rotuló con el clasificador éxito profesional a aquellos diputados que se desempeñaban prósperamente en lo relacionado con sus estudios (p. ej., si el diputado estudió derecho y su profesión era la de abogado o notario, se considera un profesionista exitoso; si estudio una licenciatura en educación primaria y se desempeñaba como profesor, etc.). En cambio, se rotuló con experiencia profesional a aquellos diputados que o bien tenían una profesión discordante con sus estudios o bien habían sido empleados temporales (p. ej., si tenían alguna licenciatura trunca y se desempeñaban como empleados o si tenían estudios básicos y trabajaban temporalmente como secretarias o camioneros, etc.). Por último, bajo el clasificador sin éxito profesional quedaron agrupados quienes se han dedicado exclusivamente a la política y no han tendido experiencia en el sector privado (p.ej., los servidores públicos con carreras truncas o, si terminadas, nunca ejercidas como profesión). Siguiendo estas tres especificaciones, se reveló que solo el 
$55 \%$ de los diputados analizados fue exitoso antes de entrar en la política, 19\% realizó algún trabajo en el sector privado y $24 \%$ nunca ha conseguido algún tipo de triunfo profesional en el sector privado.

Gráfica 3. Profesión exitosa antes de entrar en política

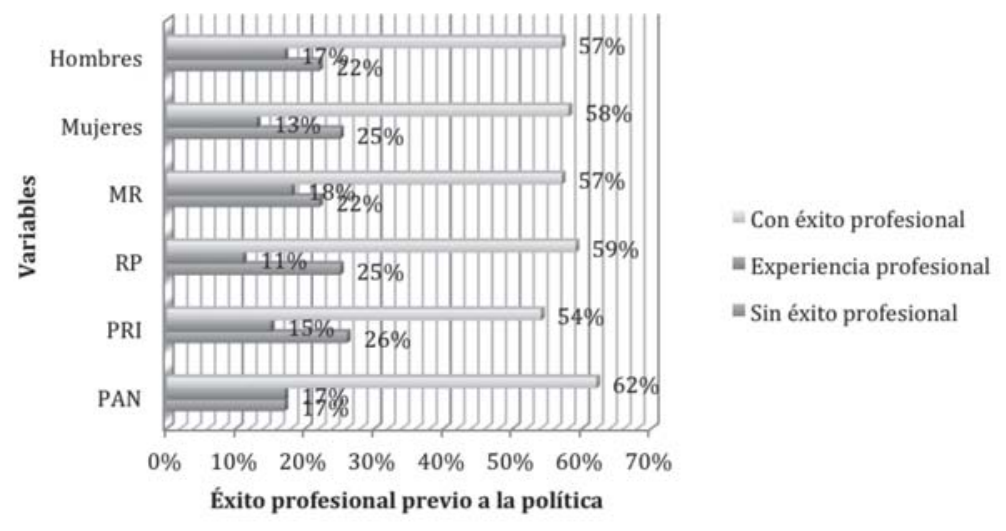

n=PAN (141), PRI (241), RP (126), MR (256), hombres (280), mujeres (102)

Por otra parte, al examinar las variables que más influyen en este rubro, se observó que el partido político parece ser la más importante, pues los diputados electos por el PAN han triunfado más en el sector privado que los electos por el PRI. Las otras variables no muestran grande influencia, pero los otros diputados que cuentan con mayor porcentaje sin éxito profesional son las mujeres y los electos por representación proporcional (RP), lo cual nos lleva a generalizar que las mujeres y los diputados por RP son en promedio los que menos éxito privado tienen antes de ser beneficiados con un puesto público.

\section{Coincidencia de estudios y comisión legislativa}

Además de la educación, el grado educativo y el éxito profesional, ¿de qué manera estos elementos son reflejados 
Perfil político de los diputados mexicanos federales del PAN y PRI de la LXI Legislatura: apuntes para un estudio cualitativo de los políticos

en el trabajo legislativo? Para analizar esta influencia se analizaron los diputados federales cuyos estudios académicos o profesión coinciden con el nombre o tema de la comisión legislativa. Visto que los diputados pertenecen a varias comisiones, se tomó en cuenta que al menos una de ellas coincidiera con su formación académica (p.ej., un ingeniero ambiental en la comisión de temas ambientales; un abogado en la comisión de justicia; un profesor en la comisión de educación).

Gráfica 4. Coincidencia de grado académico o experiencia profesional y comisión legislativa

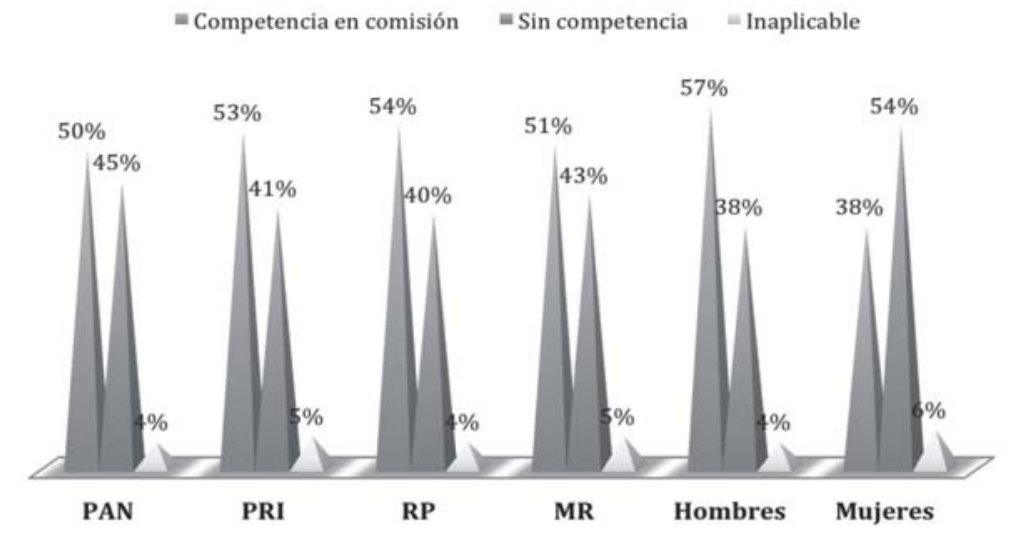

$\mathrm{n}=$ PAN (141), PRI (241), RP (126), MR (256), hombres (280), mujeres (102)

Más de la mitad de los diputados (52\%) se encarga de una comisión que tiene que ver con sus estudios, pero un preocupante $43 \%$ está en comisiones que no tienen nada que ver con su formación académica o experiencia profesional. El 5\% ocupa comisiones donde es inaplicable valorar si sus estudios coinciden con la comisión (p.ej., filosofía). Las variables se mantienen estables, excepto en la de género. La mayoría de las mujeres se encuentran en comisiones para las que no están preparadas académica o profesionalmente. 


\section{La trayectoria política de los diputados federales}

Se analizaron los siguientes indicadores de trayectoria política: primera socialización con la política, antecedentes familiares activos y relación con grupos de interés.

\section{Primera socialización en la política}

Para observar la primera socialización con la política se registró la primera actividad de los diputados federales en su vida política.

Tabla 1. Primera socialización con la política de los diputados analizados ${ }^{8}$

\begin{tabular}{ccccc} 
Activistas/ & Militantes/ & Asociativas/ & Apoyo & Acceso \\
estudiantes & partidistas & grupos de interés & particular & directo \\
$4 \%$ & $43 \%$ & $16 \%$ & $10 \%$ & $24 \%$ \\
\hline
\end{tabular}

El 43\% ingresó a partir de actividades relacionadas con los partidos políticos, el 16\% se formó en grupos de interés (sindical o patronal), 10\% inició su carrera política apoyando a un político en particular o como primera dama de su marido político, el $24 \%$ solo tiene registrado un cargo público como primera actividad. De este último grupo no se tuvo acceso a ningún dato relacionado con ninguna otra primera participación política.

8. El rubro Activistas/estudiantes incluye activistas de distintas ONG y estudiantes activos políticamente dentro de su universidad. Militantes/partidistas incluye élites partidistas locales y nacionales y militantes. Asociativas/grupos de interés incluye a aquellos que han formado su carrera política dentro de un sindicato o asociación de empresarios o grupo religioso. Apoyo particular incluye a quienes iniciaron con un político en particular. Acceso directo incluye a aquellos en cuya trayectoria aparece un cargo público como primera actividad. 
Perfil político de los diputados mexicanos federales del PAN y PRI de la LXI Legislatura: apuntes para un estudio cualitativo de los políticos

Gráfica 5. Primera socialización con la política por partido, tipo de elección y género

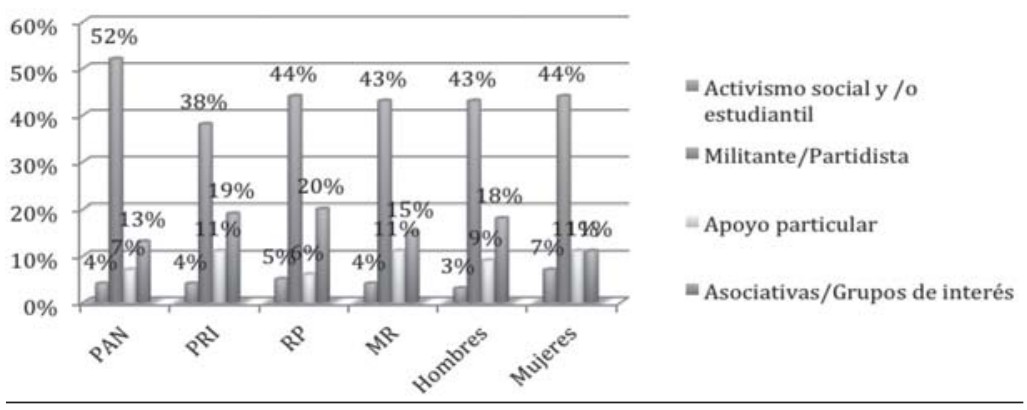

n=PAN (141), PRI (241), RP (126), MR (256), hombres (280) y mujeres (102)

En cuanto a las variables que más influyen en las diferentes formas de acceder a la política, el partido político muestra la mayor diferencia. La mayoría de los diputados del PAN (52\%) inició como militante o en actividades partidistas, mientras del PRI solo lo hizo el 38\%. Los diputados que iniciaron su carrera política en grupos de interés como asociaciones sindicales o patronales representan un alto porcentaje sobre todo entre los electos por RP, los pertenecientes al PRI y los hombres, por encima de las demás variables.

\section{Antecedentes familiares}

Otro aspecto que ha sido muy analizado en los países recientemente democratizados es la presencia en el Recinto Legislativo de diputados federales con antecedentes familiares activos en la política. Para autores como Gehlbach y Sonin (2004) se ha convertido en un indicador de compadrazgo y de oportunismo. Sin duda, además de los mentores, los antecedentes familiares facilitan el ingreso a la política. Por otro lado, para autores como Alcántara, estos no conforman un indicador fuerte, ya que no todos los hijos de un político se inclinan por la función pública, por lo que está 
implícito un interés o una vocación política que va más allá del mero parentesco.

Aun así, el porcentaje de diputados con familiares en un recinto legislativo varía según el país y debe tomarse en cuenta como un indicador importante de democratización. En la Cámara de Diputados en México los diputados del PAN y del PRI que cuentan con familiares activos en la política local y nacional (a nivel de presidencia municipal, gobernadores y/o personajes políticos nacionales) son 68 , es decir, el 18\% del total de los diputados analizados.

Gráfica 6. Antecedentes familiares por partido, tipo de elección y género

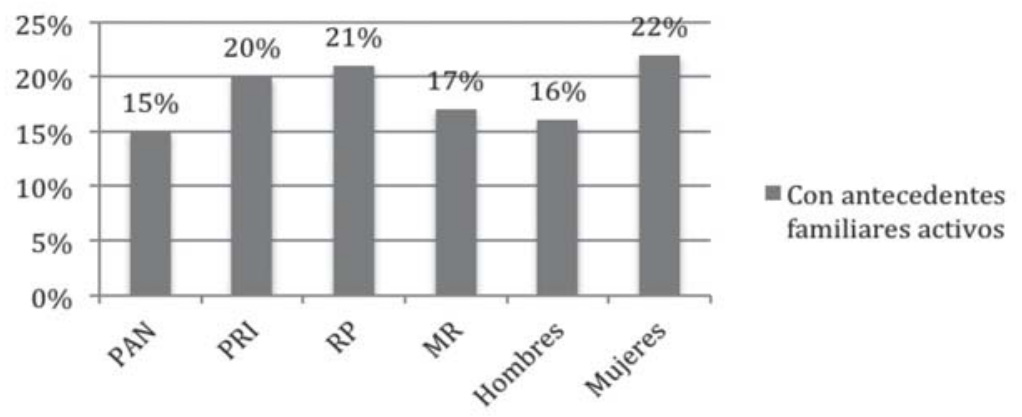

n=PAN (141), PRI (241), RP (126), MR (256), hombres (280) y mujeres (102)

Aquellas variables que más relación tienen con los antecedentes familiares son la de las mujeres, la de los diputados electos por RP y la de los diputados del PRI. Pero siguiendo con las críticas al determinismo de la familia como condición del oportunismo, se amplía el análisis a la primera participación política de los diputados con antecedentes familiares. De los 65 diputados analizados, solamente 33 hicieron trabajo voluntario antes de acceder al cargo público en el partido político. Los otros 34 accedieron directamente a un cargo de confianza. 
Perfil político de los diputados mexicanos federales del PAN y PRI de la LXI Legislatura: apuntes para un estudio cualitativo de los políticos

Gráfica 7. Primera participación política de diputados con familiares

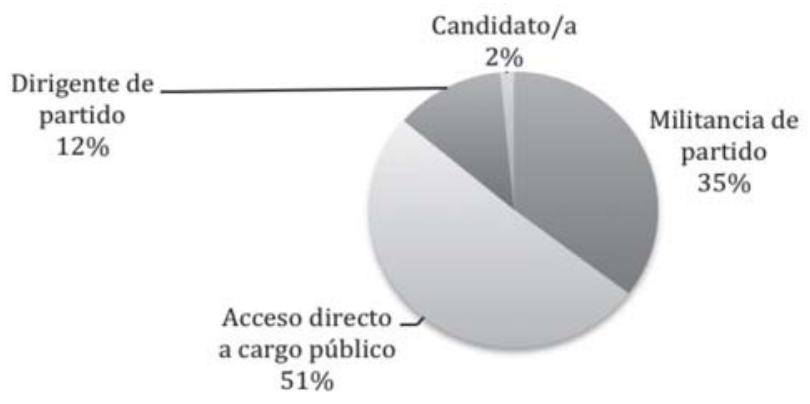

$\mathrm{n}=65$

En México, muchos de los diputados federales con familiares en la política han ingresado desde muy jóvenes a los cargos y sin una trayectoria que los respalde. Esto nos indica la importancia de analizar este indicador en un contexto determinado y en relación a otras variables, para poder observar los fenómenos de compadrazgo y de oportunismo en las carreras políticas.

\section{Antecedentes en grupos de interés}

Respecto a los grupos de interés en el Congreso Mexicano, hay que agregar que estos forman parte de una tradición latinoamericana, en cuanto a la naturaleza de nuestros partidos políticos, y por ello deben observarse como un componente de los partidos políticos y no de los diputados individuales. ${ }^{9}$ En México el 16\% de los legisladores analizados

9. En el caso de México, después de la creación de los bastiones de poder del PRI durante el mandato de Lázaro Cárdenas, los sindicatos figuraron como fuertes actores en la selección de candidatos. En 1947 Miguel Alemán hizo un pequeño experimento al querer impulsar políticos más partidistas y con menos relación con los grupos de interés, pero hasta la fecha los grupos sindicales no han permitido perder tales privilegios en la política mexicana. En el caso del PAN, desde sus inicios, han sido los actores del sector privado y la Iglesia, así como el reclutamiento de empresarios. 
aprendió el arte de la política dentro de un gremio sindical o patronal y creó ahí una estructura de oportunidades para acceder al cargo público. Al analizar a estos 62 diputados que ingresaron a la política después de hacer carrera en sindicatos o en asociaciones empresariales observamos cuál fue su primer cargo político inmediato.

Gráfica 8. Primera participación política de diputados en grupos de interés

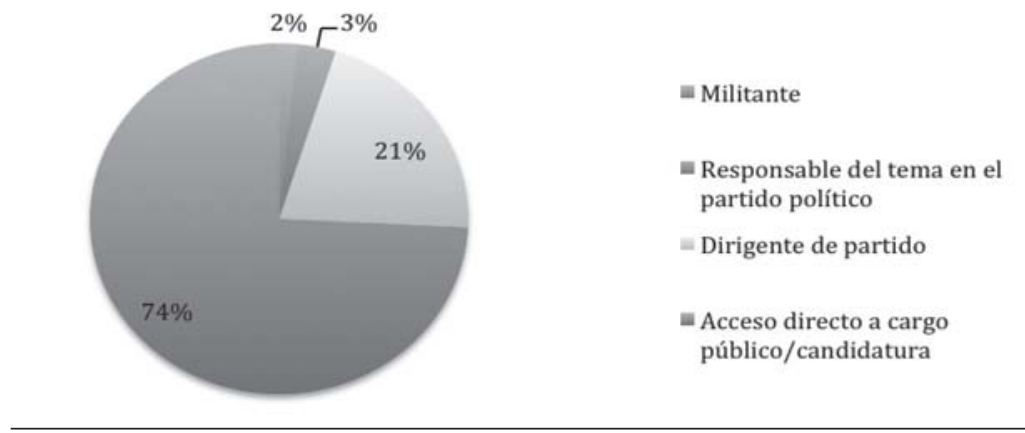

$\mathrm{n}=62$

Se puede observar el poder de los grupos de interés en la política nacional, toda vez que son capaces de nominar candidaturas e integrar las listas. Un indicador importante está en la primera participación política que tuvieron los diputados que se formaron en los grupos de interés. Las cuatro áreas son bien definidas: el $2 \%$ hizo ejercicio de militancia partidista, el 3\% fue designado responsable del tema en el partido político (sindical, de trabajo o patronal según el caso), 21\% fungió como dirigente de partido local o nacional y el $74 \%$ tuvo el acceso directo a una candidatura o cargo público sin haber realizado trabajo de partido.

El tema de los grupos de interés no reside únicamente en ser la puerta de entrada para los cargos públicos -en el caso 
Perfil político de los diputados mexicanos federales del PAN y PRI de la LXI Legislatura: apuntes para un estudio cualitativo de los políticos

aquí estudiado- de 62 diputados federales, pues hay otro aspecto que ha sido considerado de gran importancia para el análisis del oportunismo y compadrazgo en las carreras políticas: la presencia de los grupos de interés representados en el recinto legislativo, como dirigentes o como miembros. Es un hecho que al contar con diputados que están directamente relacionados con los grupos de interés la naturaleza del legislador y del representante adquiere una connotación diversa a su relación con sus votantes y representados.

Gráfica 9. Grupos de interés por partido, tipo de elección y género

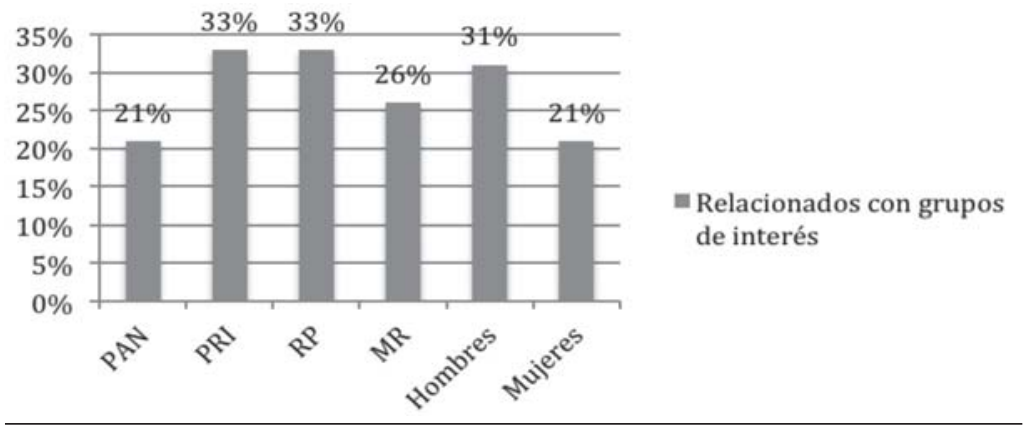

$\mathrm{n}=382$

En México, 109 de los 382 diputados analizados (el 28\%) están relacionados con grupos de interés, ya sea como integrantes o dirigentes, aunque en ellos no se haya dado su primera socialización política. Las variables que más influyen son por partido político (PRI), tipo de elección (RP) y género (hombres). Los diputados del PAN y las mujeres cuentan con el menor porcentaje de diputados relacionados con grupos de interés, pero aun así siguen conformando un considerable porcentaje: el 21\%. En el PRI abundan los sindicatos y en el PAN, las asociaciones empresariales. 


\section{Experiencia política de los diputados federales}

La tercera variable analizada se refiere a la experiencia política y para ello se observaron los siguientes indicadores: promedio de años en la política, experiencia en participación voluntaria previa al cargo público, en dirigencia partidista, en puestos de confianza y en cargos de elección popular. Es importante recalcar que la experiencia política analizada en los diputados es otro indicador que causa diferentes reacciones en la academia y en la opinión pública. En sentido estricto, un político con experiencia beneficiaría al sistema democrático más que uno sin experiencia. Si tenemos enfrente a un diputado con años de experiencia en la actividad legislativa y a un diputado que jamás ha desempeñado un puesto del género nos encontramos con reacciones muy diversas. Para los estudiosos de la democracia y de los políticos, el diputado con mayor experiencia obtendría mejores resultados en su actividad. Para la opinión pública, el diputado novato beneficiaría más a la democracia al no estar "contaminado" de lo que es la experiencia en la política. La primera opinión se refiere a una visión del político como recurso humano del sistema democrático. La segunda es una visión del político como producto de la mala forma de hacer política, percibida por los ciudadanos.

\section{Años en la política}

El promedio de años de participar en la política de los diputados del PRI y del PAN en la LXI Legislatura es de 23 años. Es decir, en promedio los legisladores iniciaron su carrera política alrededor de 1989. 
Perfil político de los diputados mexicanos federales del PAN y PRI de la LXI Legislatura: apuntes para un estudio cualitativo de los políticos

Gráfica 10. Promedio de años en la política por partido, tipo de elección y género

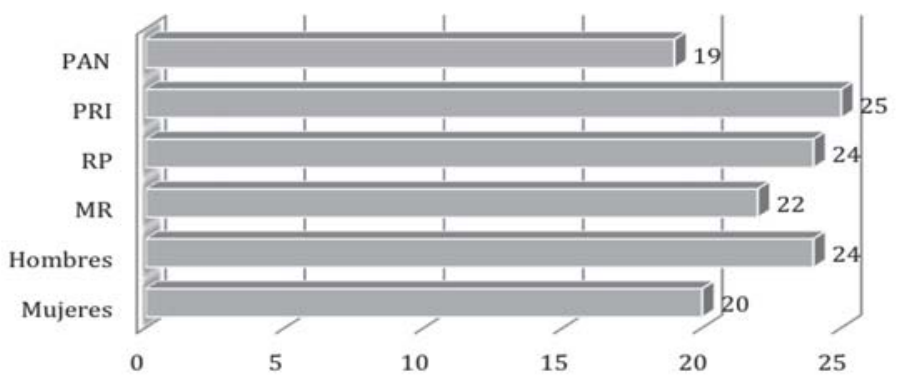

n=PAN (141), PRI (241), RP (126), MR (256), hombres (280), mujeres (102)

Sin embargo, la cantidad de años en política varía, sobre todo, según el partido político y el género. Los diputados del PRI tienen más años en la actividad política que el PAN y los hombres más que las mujeres.

Gráfica 11. Distribución de años de experiencia en la política en los diputados analizados

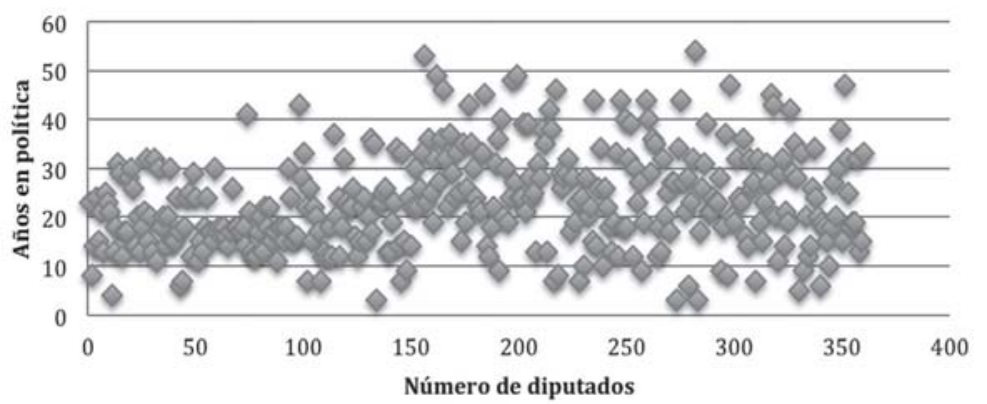

n=357 (No se encontró información de 25 de los 382 perfiles estudiados)

La gráfica de distribución nos muestra de forma más clara los años en la política con los que cuentan los diputados analizados. La mayoría se concentra en el rango que va 
entre los 10 y los 30 años de hacer política; pocos superan el rango que va de los 40 a los 50 años; y escasos son los que se han dedicado a la política durante menos de 10 años.

Por otro lado, el trabajo voluntario anterior a la obtención de un cargo político es un indicador valorado por los académicos que insisten en la vocación política. Se considera la oportunidad de la clase política establecida para probar las capacidades políticas e intelectuales de los futuros public officers. Solo 202 de los 382 diputados analizados realizaron trabajo voluntario antes de ocupar un cargo público, o sea, el 53\%. El resto o bien había ocupado cargos públicos de confianza o bien era trabajador del servicio público.

Gráfica 12. Trabajo voluntario/militancia antes de cargo político, por partido, tipo de elección y género

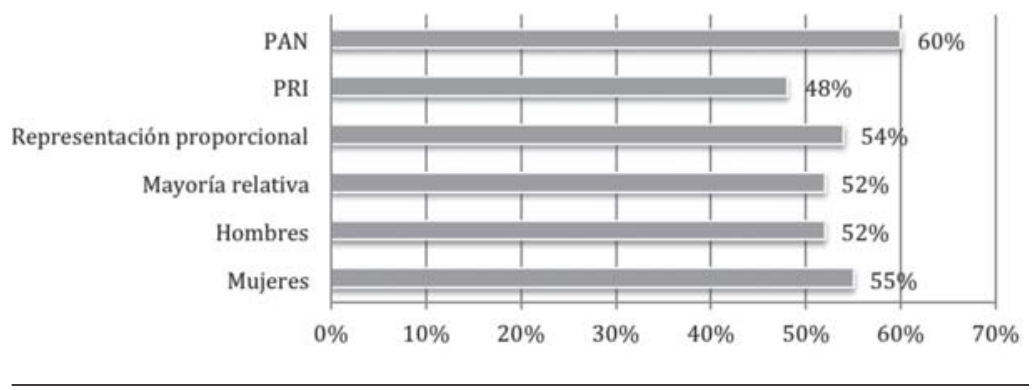

n=PAN (141), PRI (241), RP (126), MR (256), hombres (280), mujeres (102)

Las diferencias son, sobre todo, entre los partidos políticos, ya que los diputados del PAN han realizado más participación voluntaria que los del PRI. Por pocos puntos porcentuales, los diputados electos por RP y las mujeres superan el trabajo voluntario antes de obtener un puesto público respecto a los electos por MR y los hombres. La experiencia en la dirigencia partidista tiene que ver con la capacidad de liderazgo y responsabilidad, así como con la capacidad institucional de los diputados. En este sentido, se adquieren 
Perfil político de los diputados mexicanos federales del PAN y PRI de la LXI Legislatura: apuntes para un estudio cualitativo de los políticos

compromisos con la organización de los partidos políticos como instituciones políticas en el contexto democrático.

Gráfica 13. Dirigencia partidista por partido, tipo de elección y género

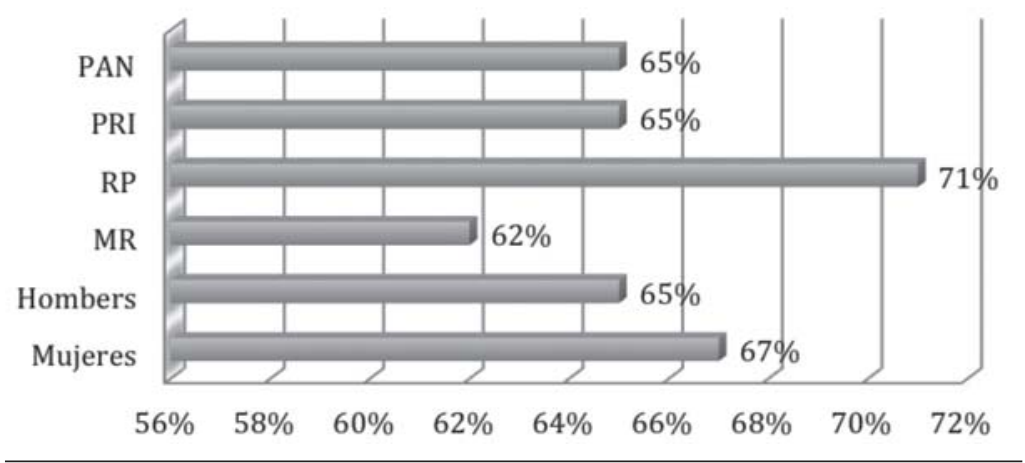

n=PAN (141), PRI (241), RP (126), MR (256), hombres (280), mujeres (102)

En la LXI Legislatura, 250 de los 382 diputados (el 65\%) han ejercido la dirigencia partidista. En cuanto al análisis con otras variables, no existen grandes diferencias entre partidos políticos o géneros. La variable más influyente es el tipo de elección, ya que, de los diputados electos por RP, el 71\% ha ejercido la dirigencia partidista. Esta observación coincide con la naturaleza de los diputados de representación proporcional, pues en la Cámara son, sobre todo, representantes de los partidos políticos.

\section{Puestos de confianza}

Por otra parte, la naturaleza del "puesto de confianza" ha sido muy poco desarrollada en la literatura sobre la clase política. Tiende a ser un indicador de oportunismo o de compadrazgo, pero también de habilidades para llevar a cabo tareas ejecutivas en un trabajo de equipo. La mayoría de los diputados analizados han realizado tareas de este 
tipo, pues de 382 diputados, 266 han ocupado puestos de confianza a lo largo de su carrera política, es decir, el 69\%. Las diferencias en este rubro son sobre todo en cuanto al partido político: $74 \%$ del PAN y $67 \%$ del PRI; por tipo de elección, 70\% los de RP y 69\% de MR; mayor en los hombres (con un 71\%) que en las mujeres (el 66\%).

En cuanto al tipo de cargos de designación entre los diputados analizados, abundan los puestos de confianza en la administración pública local entre todas las variables analizadas. Sin embargo, es también importante la cantidad de puestos de confianza particular, la cual suele ser muy alta en el PRI y entre los hombres. La experiencia en este tipo de puestos en la administración pública nacional es más común entre los diputados de RP.

Gráfica 14. Tipo de cargos de designación ocupados por partido, tipo de elección y género

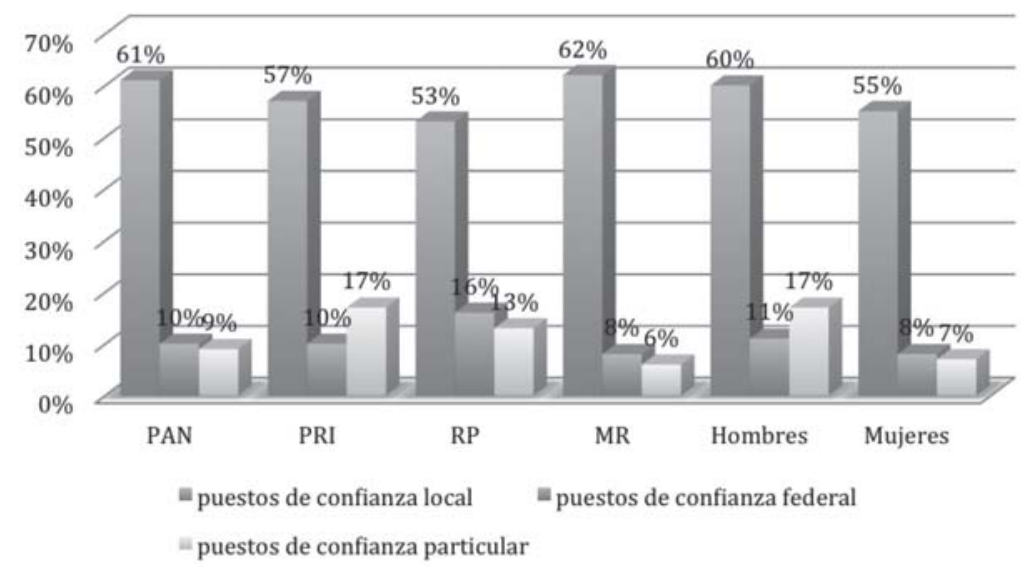

Nota: Se cuenta el número de diputados con experiencia en cada uno de los puestos de confianza. Puede haber diputados con más de un tipo de experiencia y se cuantifica como unidad en cada categoría. 
Perfil político de los diputados mexicanos federales del PAN y PRI de la LXI Legislatura: apuntes para un estudio cualitativo de los políticos

La experiencia en un cargo de elección popular beneficia tanto a los ciudadanos como al ejercicio del cargo público. Para autores como Mattozzi y Merlo (2007) la experiencia en los cargos de elección popular favorece a los ciudadanos al contar con representantes y legisladores federales que ya han estado bajo el escrutinio ciudadano, por lo que aumenta la información disponible del candidato. En cuanto al ejercicio del cargo público, ser un político con experiencia previa en un cargo de elección popular significa ser un candidato más consciente de la importancia de realizar bien el trabajo para seguir gozando de una buena opinión pública.

\section{Gráfica 15. Cargos de elección previa por partido,} tipo de elección y género

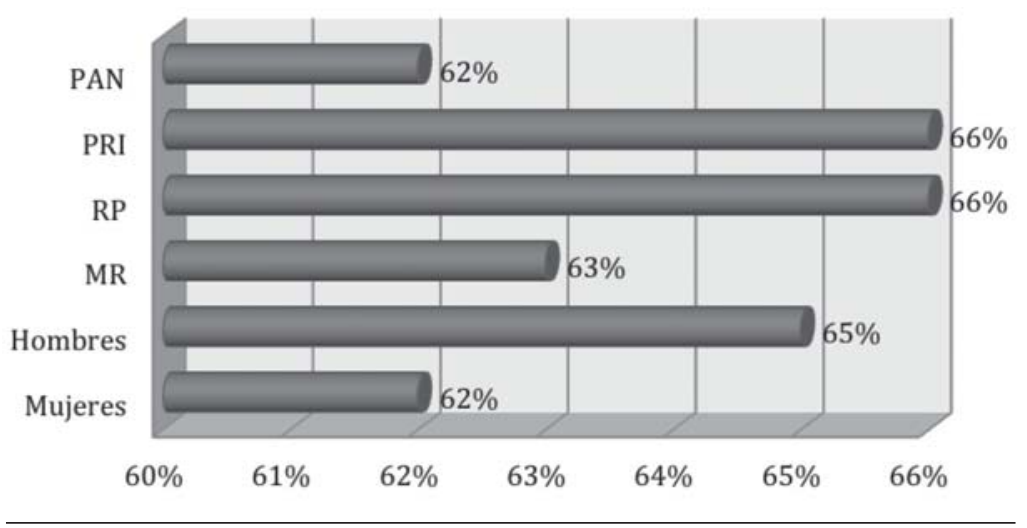

n=PAN (141), PRI (241), RP (126), MR (256), hombres (280), mujeres (102)

Sin embargo, en México, únicamente 245 de los 382 diputados federales de la LXI Legislatura analizados han sido (al menos) una vez electos, lo cual en otras palabras significa que solo el $64 \%$ ha ocupado un cargo de elección popular, y que un preocupante $36 \%$ está ocupando por primera vez un puesto de elección en un recinto de tan gran importancia para la política nacional. 


\section{Conclusiones}

A pesar de la democratización institucional aún queda mucho por cambiar en las prácticas de la política que persisten en los actores y en las élites, tanto mexicanas como latinoamericanas, especialmente en cuanto a la democratización de los partidos políticos, el rol de los grupos de interés en la política y la profesionalización de la clase política. Los teóricos de la democracia han enfatizado, si bien someramente, la importancia de la clase política y de sus actores, aunque por mucho tiempo se ha abandonado la observación de su evolución en la academia. En la actualidad, las teorías de reclutamiento y de carreras políticas se están desarrollando para observar dicho fenómeno que atañe a las instituciones políticas formadoras de los actores: los partidos políticos y las instituciones representativas.

El concepto quality politician, manejado en la literatura de la economía política, se está desarrollando en términos del buen reclutamiento político y de la calidad de la carrera política como dos elementos favorables a la democracia y a su desarrollo. Los principales responsables de una buena carrera política serían los factores de política establecida, partidos políticos, bajo nivel de oportunismo, independencia de grupos de interés y funcionamiento de las instituciones representativas.

Para analizar el estado de calidad de la carrera política de nuestros representantes, se seleccionó una muestra de 382 diputados del PAN y del PRI en la LXI Legislatura. El análisis se hizo en tres dimensiones de la carrera política de calidad: competencias personales de los legisladores, reclutamiento político y experiencia. Las variables independientes fueron las de partido político, tipo de elección y género.

Entonces, se puede concluir que la clase política recluta sobre todo a personas que han tenido éxito en su carrera profesional -aunque hoy día estas conformen solamente el 
Perfil político de los diputados mexicanos federales del PAN y PRI de la LXI Legislatura: apuntes para un estudio cualitativo de los políticos

$60 \%$ de los perfiles revisados-y que en la organización de las comisiones legislativas las instituciones de representación logran que casi el 60\% de los diputados ocupe las comisiones que se encargan de tratar los temas en los cuales está especializado.

En cuanto al reclutamiento, es preocupante la cantidad de diputados que entran por vías de grupos de interés y de apoyo particular, así como el bajo porcentaje de activistas que llegan a influir en la política nacional. Del mismo modo, aquellos diputados con antecedentes familiares conforman un alto porcentaje (18\%) para un país que busca la democratización en sus instituciones y elecciones. El 28\% de los diputados relacionados con grupos de presión limita y desdibuja el deber de los legisladores respecto a sus votantes y representados. Los sindicatos y las asociaciones patronales ejercen un gran poder en la política mexicana sobre cualquier otra asociación civil o ciudadana.

Tenemos una alternancia de 12 años, pero políticos que en promedio tienen 23 años haciendo política, por lo que es necesario un análisis de los valores democráticos de nuestros políticos. Apenas poco más de la mitad de los diputados analizados realizaron trabajo voluntario antes de ocupar un cargo público, por lo cual el monitoreo de la clase política a los próximos políticos es muy baja. La experiencia en dirigencia partidista se mantiene como los otros porcentajes: rondando el 60\%; mientras que en los puestos de confianza esta sube casi al 70\%. Por otro lado, contamos con alrededor del $40 \%$ de diputados novatos que nunca antes habían sido votados ni conocidos por los ciudadanos.

Todos estos resultados provocan una reflexión sobre la importancia de las carreras políticas para la democracia mexicana. El peso de los partidos políticos y su naturaleza interna -relación con grupos de interés, selección de candidatos- es aún muy fuerte. Por ello, es importante que en los estudios legislativos se tomen en cuenta indicadores 
sobre los diputados como recursos humanos, así como la necesidad de su profesionalización y la calidad de sus carreras políticas. Los actores políticos son la clave de que las instituciones democráticas perduren y se desarrollen hacia una mejor calidad.

Fecha de recepción: 19 de mayo de 2013

Fecha de aceptación: 29 de enero de 2014

Bibliografía

Ai Camp, Roderic, 2002, Mexico's mandarins. Crafting a power elite for the twenty-first century, University of California Press, California.

Alcántara, Manuel, 2008a, "Some reflections on the relationship between politicians and politics in Latin America after twenty five years of democracy", Jean Monnet/ Robert Schuman Paper Series, vol. 8, núm. I.

, 2008b, "The political competence of representatives in Latin America: an analysis of eleven national cases", en la Annual Meeting of the American Political Science Association (agosto 28-3I). 2009, “Calidad de los políticos y calidad de la política”, en José Reynoso Núñez y Herminio Sánchez de la Barquera y Arroyo (coords.), La democracia en su contexto. Estudios en homenaje a Dieter Nohlen en su septuagésimo aniversario. México, Universidad Nacional Autónoma de México, pp.427-450.

Besley, Timothy, 2004, "Paying Politicians: Theory and Evidence", Journal of the European Economic Association, vol. 2, núm. 2-3, pp. 193-215

Besley T., R. Pande, L. Rahman y V. Rao, 2004, “The Politics of Public Good Provision: Evidence from Indian Local Governments", Journal of the European Economic Association, vol. 2, núm. 2-3, pp. 4I6-426. 
Perfil político de los diputados mexicanos federales del PAN y PRI de la LXI Legislatura: apuntes para un estudio cualitativo de los políticos

, 2005, "Political Selection and the Quality of Governments: Evidence from South India", Working Paper, núm. 92I.

Casellia y Morelli, 200I, "Bad politicians”, Journal of Public Economics, Elsevier, vol. 88, núm. 3-4, pp. 759-782.

Crouch, Colin, 2004, Posdemocracia, Taurus.

Dahl, Robert, 197I, Polyarchy: Participation and Opposition, Yale University Press.

Dal Bo y Di Tella, 2003,“'Plata o Plomo': Bribe and Punishment in a Theory of Political Influence", Working Papers 2002-28.

Galasso,Vincenzo y Nannicini Tommaso, 2009,“Competing on Good Politicians", Bocconi University, IGIER and CEPR Bocconi University, IGIER and IZA Discussion Paper, núm. 4282.

Gehlback y Sonin, 2004, “Businessman Candidates”, Econometric Society North American Summer Meetings, 178.

Higley, John y Richard Gunther, 1992, Elites and Democratic Consolidation in Latin America and Southern Europe, Cambridge University Press.

Higley, J. y J. Pakulski, 2007, "Elite and Leadership Change in Liberal Democracies", Comparative Sociology, vol. 6, Pp. 6-26.

Linz, Juan, 1997, "Some thoughts on the victory and future of democracy”, en Axel Hadenius, Democracy's victory and crisis, Cambridge University Press.

Mattozzi y Merlo, 2007, "The Transparency of Politics and the Quality of Politicians”, The American Economic Review, vol. 97, núm. 2, pp. 3। I-3। 5.

Morlino, 2004, “'Good' and 'bad' democracies: how to conduct research into the quality of democracy", Journal of Communist Studies and Transition Politics, vol. 20, num. I, 5. ,2004b, “What is a 'good' democracy?", Democratization, vol. II, núm. 5, I0.

Estado 8 No. 60 
Bibliografía

Norris, Pippa, 1997, Passages to power: legislative recruitment in advanced democracies.

Pareto,Vilfredo, 1916, Trattato Di Sociologia Generale, Milano.

Pasquino, Gianfranco, 1999, La classe politica, II Mulino, Bologna.

Pharr y Putnam (eds.), 2000, Disaffected Democracies:What's Troubling the Trilateral Countries?, Princeton University Press, Princeton.

Pennings y Hazan, 2010,"Democratizing candidate selection, causes and effects”, en Hazan y Rahat, Democracy within parties. Candidate selection methods and their political consequences.

Poutvaara P.y T.Takalo, 2007,“Candidate quality”, International Tax and Public Finance, núm. I4, pp. 7-27.

Przerowski, Adam, Susan Stokes y Bernard Manin (eds.), 1999, Democracy, Accountability and Representation, Cambridge University Press.

Rehfeld, 2010, “On Quotas and Qualifications for Office”, en lan Shapiro, Susan Stokes, Elisabeth Woods y Alexander Kirschner (eds.), Political Representation, Cambridge University Press, Nueva York.

Sartori, 1987, The theory of democracy revisited, Chatham, Nueva Jersey.

Schlesinger, J.A., 1966, Ambition and Politics. Political Careers in the United States, Rand McNally y Company, Chicago.

Siavelis y Morgenstern (eds.), 2008, Pathways to power the Pennsylvania State University.

Thompson, Dennis F., 1987, Political ethics and public office, Harvard University Press.

Weber, Max, 200I [1919], El politico y el científico, Alianza Editorial, Madrid. 